\title{
An assessment of parents' knowledge and awareness regarding paracetamol use in children: a cross-sectional study from Palestine
}

Aiman Daifallah', Ruba Jabr ${ }^{1}$, Faraj Al-Tawil ${ }^{1}$, Moutaz Elkourdi ${ }^{1}$, Ziad Salman ${ }^{1}$, Amer Koni ${ }^{1}$, Ahmad Samara², Samah W. Al-Jabi ${ }^{1}$ and Sa'ed H. Zyoud ${ }^{1,3,4^{*}}$ (i)

\begin{abstract}
Background: Paracetamol, also known as acetaminophen, is one of the most common antipyretic and analgesic over-the-counter (OTC) medicines administered to children due to its efficacy, safety, and availability in many pharmaceutical forms, including suppositories, syrup, and drops. Parents frequently administer the wrong dose of paracetamol by mistake for their children, as reported by many previous studies. We aimed in this study to assess parents' knowledge, attitudes, and practice regarding paracetamol dosing and toxicity, as well as their awareness regarding paracetamol-containing products.
\end{abstract}

Methods: This was a cross-sectional study that targeted parents of children seeking healthcare services at primary health care centers in the Nablus area in the West Bank, Palestine. We used questionnaire-based interviews with parents for data collection.

Results: A total of 300 parents were included in the study. Most of the caregivers surveyed were (87\%) females (mothers). About half the parents (50.9\%) reported previously using paracetamol as an antipyretic in children under the age of six. A quarter (25.4\%) preferred the syrup forms, while 33.8\% preferred the suppository dosage form. Medical personnel was the primary source of information for half the caregivers (51.2\%). The mean knowledge score about paracetamol was $2.1(S D=1.4)$ out of 6 , and the median was 2.0 with an interquartile range of 1.0-3.0. Two hundred seventy-four (95.5\%) of the participants scored less than $80 \%$ and were considered to have insufficient knowledge. Only 50.9\% of parents recognized that paracetamol overdose could result in serious harm.

\footnotetext{
*Correspondence: saedzyoud@yahoo.com; saedzyoud@najah.edu

${ }^{1}$ Department of Clinical and Community Pharmacy, Department of

Pharmacy, College of Medicine and Health Sciences, An-Najah National University, Nablus 44839, Palestine

${ }^{3}$ Poison Control and Drug Information Center (PCDIC), College of Medicine and Health Sciences, An-Najah National University, Nablus 44839, Palestine

Full list of author information is available at the end of the article
}

(c) The Author(s). 2021 Open Access This article is licensed under a Creative Commons Attribution 4.0 International License, which permits use, sharing, adaptation, distribution and reproduction in any medium or format, as long as you give appropriate credit to the original author(s) and the source, provide a link to the Creative Commons licence, and indicate if changes were made. The images or other third party material in this article are included in the article's Creative Commons licence, unless indicated otherwise in a credit line to the material. If material is not included in the article's Creative Commons licence and your intended use is not permitted by statutory regulation or exceeds the permitted use, you will need to obtain permission directly from the copyright holder. To view a copy of this licence, visit http://creativecommons.org/licenses/by/4.0/ The Creative Commons Public Domain Dedication waiver (http://creativecommons.org/publicdomain/zero/1.0/) applies to the data made available in this article, unless otherwise stated in a credit line to the data. 
(Continued from previous page)

Conclusions: We found a serious lack of knowledge regarding paracetamol dosing, administration, and potential toxicity among Palestinian parents. We recommend raising awareness regarding this problem among healthcare providers and authorities and working on plans that aim to provide caregivers with accurate and adequate information on dosing, formulation, side effects, and other aspects of paracetamol use, as well as developing effective educational plans targeting healthcare providers, as well as the public.

Keywords: Paracetamol, Acetaminophen, Knowledge, Awareness, Children, Parents, Toxicity, Palestine,

\section{Background}

Paracetamol, also known as acetaminophen, is one of the most common antipyretic and analgesic over-thecounter (OTC) medicines administered to children due to its efficacy, safety, and availability in many pharmaceutical forms, including suppositories, syrup, and drops [1]. Some parents lack the necessary knowledge concerning paracetamol administration, adverse effects, dosing, and toxicity, which may lead to paracetamol underdosing or over-dosing, which both have negative consequences on the health of children and community healthcare system outcomes [2-5]. For example, underdosing may lead to inadequate fever management and further unnecessary consultation; making incorrect assumptions about fever causes increasing healthcare costs, resulting in unnecessary use of antibiotics [6, 7]. On the other hand, overdosing may cause dangerous side effects and toxicity, leading to hepatotoxicity and liver failure, especially in patients at risk for such injury [8-10].

As paracetamol is readily available in many brands and combinations, accidental overdose is potentially lifethreatening and should be considered a significant public health concern [11-13]. Rising rates of intentional and accidental paracetamol poisoning in childhood [14, 15] make it imperative that the public be aware of paracetamol overdose risks. Parents frequently administer the wrong dose of paracetamol by mistake for their children, as reported by many previous studies. Many contributing factors for this problem have been suggested, including the widespread use of paracetamol, its availability in many forms, low levels of awareness regarding the active components in paracetamol products, and misconceptions about the potential of OTC medications for harm [3, 4, 16-23]. Additionally, many studies also noted that parents have inadequate knowledge of paracetamol use and poor awareness of its toxicity [3-5, 16-25].

Due to these important public health implications, parents' knowledge about paracetamol is important as paracetamol is considered the most encountered individual pain medication used $(42.2 \%$ of all pain medications used) in Palestine [15, 26-28]. Furthermore, paracetamol poisoning was the most frequently reported case by emergency departments in Palestine [29]. Additionally, paracetamol toxicity lies at the top of the medication poisoning list in many countries [30,31]. A US study from 2011 found that both intentional and accidental poisoning of paracetamol continues to be a major public health problem [32]. Parents may seek information about paracetamol from health care professionals (doctors or pharmacists), medication package inserts and product labels, advertisements, the internet, family and friends, and drug call centers [33, 34].

A previous study conducted in Palestine showed that medications, mainly pain medications, are responsible for accidental poisoning and suicidal cases [26]. Indeed, this study analysed the calls received by the Palestinian Poison Control and Drug Information Center (PCDIC) over 2 years and revealed that unintentional poisoning was the leading reason for the calls $(62.8 \%)$ and, importantly, the majority of victims (54.0\%) were under the age of 6 years [32]. Another analysis of a medical call center conducted in Australia found that consumers have many questions and concerns regarding paracetamol safety and efficacy underestimated by healthcare professionals [34]. A study that evaluated Palestinian parents' knowledge, attitudes and practice regarding self-medication for their children found that $67.4 \%$ of responders believed that paracetamol is safe, even in very high doses [35]. This misconception is very dangerous because high doses of paracetamol can lead to liver damage.

In Palestine, many studies have assessed medication use in children [35-39], but none addressed parents' awareness and knowledge regarding paracetamol dosage forms. Therefore, in the current study, we aimed to assess parents' knowledge, attitudes, and practice regarding paracetamol dosing and toxicity, as well as their awareness regarding paracetamol-containing products. Since accidental ingestions have been linked with a greater risk of hepatotoxicity, awareness regarding paracetamolcontaining products is of public health importance. Our study results may be used as a basis for a more extensive survey, which can help responsible authorities implement regular educational programs and make appropriate interventions according to the study results. Moreover, this study's results offer vital data for local health-related policy-makers and educational institutions in their efforts to achieve evidence-based and safe 
medical practices by increasing parents' awareness and knowledge on the topic of this study.

\section{Methods}

\section{Study design and setting}

A cross-sectional study was conducted in primary healthcare centers in the Nablus area (including Nablus city and nearby refugee camps and villages). We collected data from pediatrics' health care centers, where parents went to vaccinate their children regularly and then focused on dates when we could hire the needed sample. Most of the cases that come to these clinics do not have serious symptoms. Clearly, cases with serious symptoms mainly visit the emergency department. Data was collected over a 3week from December 2016 in mid-winter. Four primary health care centers were selected for this study. These centres have the following in common, making them ideal as a field of research [37-40]: (1) provide a complete primary health care package; (2) serve a wide number of patients; and (3) cover three types of populations in the area (rural, urban, and Palestinian refugee camps).

\section{Sample size and sampling technique}

The total population of the Nablus area was 340,117, with 187,839 living in Nablus city. During the study period, the approximate number of parents visiting the pediatrics' health care centers for vaccination was 1200 . This number was used as a population to decide the sample size needed for analysis. The sample was calculated by the Daniel formula [41], $n=\mathrm{Z}^{2 * *} \mathrm{P}(1-\mathrm{P}) / \mathrm{d}^{2}$, where $n=$ sample to be calculated, $\mathrm{z}=1.96$ (CI of 95\%), $\mathrm{d}=0.05$ (absolute precision as a margin of error), $P=0.5$ expected prevalence or response distribution. Thus, the calculated sample size was around 385 subjects. This number was used as the sample size when the population of the study is more than 10,000. In our study the sample size needs to be adjusted as our population is relatively small, $N=1200(N<10,000)$. Therefore, the required minimum sample will be obtained by using the following equation; adjusted sample $=\mathrm{n} /(1+(\mathrm{n} / \mathrm{N}))$, where $\mathrm{n}$ : is the sample size when the population is more than 10,000 and $\mathrm{N}$ is the population. The adjusted sample was around 292 subjects. In addition, to ensure adequate power and enhance study reliability, the target sample size was increased to 300 participants. We selected all primary healthcare centers which are distributed in the study area covering all geographical clusters to obtain a sample with adequate representation. The goal of the sampling procedure was to have an equal sample size from each primary health center, in which a sample of 75 parents was collected using a convenience sampling technique from each primary health center.

\section{Inclusion and exclusion criteria}

In the current study, we included parents between the ages of 19 and 48 years who parented one or more children aged 6 years or younger. Subjects were also required to read and agree to the study's informed consent. In some cases where the participants were with no formal education, we provided them with verbal informed consent with a complete explanation of all study aspects. After parents agreed to participate, an appropriate time and comfortable place for the interview was selected. We excluded subjects whose children had one or more chronic illnesses, such as cancer, congenital heart disease, cerebrovascular disease, psychiatric disorders, and hepatic diseases. Subjects whose children were hospitalized before for at least 5 days and were also excluded. In addition to the exclusion of pediatric emergency sites in hospitals.

\section{Data collection instrument}

Parents were interviewed using a questionnaire (Additional file 1) that was developed by retrieving and defining essential domains from the relevant literature to assess parents' knowledge, attitudes, and practice regarding paracetamol dosing and toxicity, as well as their awareness regarding paracetamol-containing products $[3-5,16-25,37]$. The interview was achieved by four pharmacists who had experience in community pharmacy practice and counseling with patients. These specialists were chosen to guarantee the language's simplicity and make the applied instrument more clear and understandable to the parents. Clearly, the investigators explained each question to the subjects throughout the interview. Moreover, to ensure the questionnaire's content validity and to confirm that the items can be understood, it was reviewed and validated by three experts in pharmacy practice. To check for any possible improvements in the questionnaire, a pilot study was performed with 15 parents, but as the chosen parents all understood the questionnaire, no adjustments were made. Initially, and before providing the participants with the questionnaire, we asked them, "Which one of you primarily provided health care to the child" and accordingly, we interviewed one parent (father or mother) in case both parents were existing.

The questionnaire contained socio-demographic items (e.g., age, gender, level of education for parents, and the number of children in the family). Initially, the parents were asked if they used paracetamol previously. Furthermore, they were shown photos of the outer box of certain products, some of which contained paracetamol, to point out the products which contain paracetamol. The purpose of these two steps was to ensure the parents know paracetamol medication. In addition, parents were asked about items regarding paracetamol dosage forms 
(suppositories, syrups, and drops) that were available in Palestine to determine the doses used and caused beyond their choice (i.e., ease of administration of the suppository dosage form). Moreover, all trade names of paracetamol available in Palestine were used in the study to avoid bias based on the variable use of these products. Finally, subjects' knowledge of paracetamol toxicity was measured by a set of multiple-choice items that covered the following topics: recommendations for a daily dose, specific side effects, and overall potential to cause harm. Importantly, we provided the parents with an educational orientation at the end of the interview for incorrect answers that may harm their children. A knowledge score was calculated as the sum of correct answers to items that covered paracetamol administration, dosing, and toxicity and ranged from 0 to 6 , with higher scores representing better knowledge.

\section{Statistical analysis}

Data were analyzed using the Statistical Package for Social Sciences (SPSS), version 21. We conducted a descriptive analysis of characteristics and question items. Frequencies and percentages were calculated for categorical variables, and means and standard deviations and/or medians and interquartile were calculated for numerical variables. Based on Bloom's cut off point, parents' overall knowledge was categorized as sufficient knowledge if the score was above $80 \%$ ( $\geq 5$ points) and poor if the score was less than $8 \%$ ( $<5$ points) [42].

\section{Results}

Socio-demographic data of parents and their children

Three-hundred parents of children aged 6 years or younger participated in this study. Most participants (87\%)

Table 1 Socio-demographic characteristics of children

\begin{tabular}{ll}
\hline Variable $^{\text {a }}$ & Frequency (\%) \\
\hline Gender & $162(54.0)$ \\
Male & $138(46.0)$ \\
Female & \\
Child order & $98(32.7)$ \\
First & $107(35.7)$ \\
Second & $56(18.7)$ \\
Third & $19(6.3)$ \\
Fourth & \\
Number of doctor's visits in the last 6 months \\
None & $10(3.3)$ \\
Once & $131(43.7)$ \\
Twice & $61(20.3)$ \\
Three times & $53(17.7)$ \\
Four times or more & $35(11.7)$ \\
\hline
\end{tabular}

${ }^{\mathrm{a}}$ There were missing data on some of the variables were female parents and three quarters (75.3\%) of mothers' age were between 19 and 30 years old. More than half of the mothers (55.3\%) had completed high school education as their highest level of education. A third of the participants (33.0\%) had two children below 18 years of age, and a half $(50.0 \%)$ had two children below 6 years of age. Of the children presenting to their parents, $54 \%$ were boys, and $43.7 \%$ had one doctor visit in the last 6 months. The participating parents and their

Table 2 Socio-demographic characteristics of parents

\begin{tabular}{ll}
\hline Variable & Frequency $(\%), \mathbf{N}=\mathbf{3 0 0}$ \\
\hline Number of children aged less than six years \\
1 child & $115(38.3)$ \\
2 children & $150(50.0)$ \\
3 children or more & $35(11.6)$ \\
Number of children aged < 18 years & \\
None & $67(22.3)$ \\
1 child & $76(25.3)$ \\
2 children & $99(33.0)$ \\
3 children & $29(9.7)$ \\
4 children or more & $28(9.3)$ \\
Fathers' age (year) & $126(42)$ \\
$21-30$ & $137(45.7)$ \\
$31-40$ & $35(11.7)$ \\
$41-56$ & $2(0.7)$ \\
Dead &
\end{tabular}

${ }^{a}$ There were missing data on some of the variables 
Table 3 Awareness regarding paracetamol products among the participants

\begin{tabular}{lc}
\hline Variable & Frequency (\%); $\boldsymbol{N}=\mathbf{3 0 0}$ \\
\hline Used paracetamol for the child without consulting a doctor \\
Yes & $152(50.7)$ \\
No & $75(25.0)$ \\
I do not know what paracetamol is & $73(24.3)$
\end{tabular}

Used one of the following products for the child

Acamoli cold
Acamoli syrup $250 \mathrm{mg} / 5 \mathrm{ml}$
Acamoli syrup $125 \mathrm{mg} / 5 \mathrm{ml}$
Acamoli supp $80 \mathrm{mg}$
Acamoli supp $150 \mathrm{mg}$
Acamoli forte supp $250 \mathrm{mg}$
Paramol infant supp
Paramol extra susp
Paramol child supp
Paramol plus
Paramol extra
Otamol syrup
Otamol supp
Flu syrup
Novimol drops
Sedamol tab
Panadol tab
Dexamol tab
Flu tab

$104(34.6)$

$101(33.7)$

$139(46.3)$

$113(37.7)$

$118(39.3)$

69 (23.0)

64 (21.3)

79 (26.3)

$112(37.3)$

$30(10.0)$

$28(9.3)$

$78(26.0)$

$68(22.7)$

$104(34.7)$

$46(15.3)$

$48(16.0)$

64 (21.3)

$31(10.3)$

$35(11.6)$

Which product(s) contain(s) paracetamol

$\begin{array}{ll}\text { Acamoli cold (available) } & 61 \text { (20.3) } \\ \text { Acamoli syrup } 250 \mathrm{mg} / 5 \mathrm{ml} \text { (available) } & 104(34.7) \\ \text { Acamoli syrup } 125 \mathrm{mg} / 5 \mathrm{ml} \text { (available) } & 136(45.3) \\ \text { Acamoli supp } 80 \mathrm{mg} \text { (available) } & 90(30.0) \\ \text { Acamoli supp } 150 \mathrm{mg} \text { (available) } & 107(35.7) \\ \text { Acamoli forte supp } 250 \mathrm{mg} \text { (available) } & 93(31.0) \\ \text { Paramol infant supp (available) } & 76(25.3) \\ \text { Paramol extra susp (available) } & 81(27.0) \\ \text { Paramol child supp (available) } & 106(35.3) \\ \text { Paramol plus (available) } & 67(22.3) \\ \text { Paramol extra tab (available) } & 71(23.7) \\ \text { Otamol syrup (available) } & 88(29.3) \\ \text { Otamol infant supp (available) } & 80(26.7) \\ \text { Flu syrup (not available) } & 41(13.7) \\ \text { Flu tab (available) } & 36(12.0) \\ \text { Novimol drops (available) } & 46(15.3) \\ \text { Trufen (not available) } & 60(20.0) \\ \text { Adcef (not available) } & 30(10.0)\end{array}$

Table 3 Awareness regarding paracetamol products among the participants (Continued)

\begin{tabular}{ll}
\hline Variable & Frequency (\%); $\mathbf{N = 3 0 0}$ \\
\hline Amoxitid (not available) & $35(11.6)$ \\
Dexamol (available) & $44(14.7)$ \\
Sedamol (available) & $46(15.3)$ \\
Acamol tab (available) & $91(30.3)$ \\
Panadol tab (available) & $96(32.0)$ \\
Moxepharm (not available) & $40(13.3)$ \\
Emegrain (available) & $32(10.7)$ \\
\hline
\end{tabular}

children's demographic features are presented in Tables 1 and 2 , respectively.

\section{Awareness regarding paracetamol products and indications}

Half the participants (50.7\%) reported previous paracetamol administration to their children without consulting a doctor (Table 3). Of the 287 participating parents who previously used paracetamol or could identify at least one paracetamol product, $50.9 \%$ reported that they used paracetamol to reduce fever, and $15.3 \%$ used it as an analgesic (Table 4). Most participants reported that using paracetamol without a prescription was the experience of the child's previous illness.

\section{Participating parents' knowledge regarding paracetamol use}

The mean knowledge score was $2.1(\mathrm{SD}=1.4)$ out of 6 , and the median was 2.0, with an interquartile range of 1.0-3.0. When asked about the maximum daily number of paracetamol administration, $42.2 \%$ of the participants answered with 3, 27.2\% answered with 4, 19.2\% answered with 2 , and $4.5 \%$ answered that it should not exceed five doses. Most (61.0\%) participants selected '4-6 $h$ ' as the time to be allowed between doses. Two hundred seventy-four (95.5\%) of the participants scored less than $80 \%$ and were considered to have insufficient

Table 4 Paracetamol indications as perceived by the participating parents

\begin{tabular}{ll}
\hline Paracetamol use & $\begin{array}{l}\text { Frequency (\%); } \mathbf{N =} \\
\mathbf{2 8 7}\end{array}$ \\
\hline Anti-pyretic & $146(50.9)$ \\
Analgesic & $44(15.3)$ \\
Sedative & $15(5.2)$ \\
Symptoms of illness (cough, flu, and & $18(6.3)$ \\
vomiting) & \\
Anti-pyretic and analgesic & $25(8.7)$ \\
Anti-pyretic and sedative & $2(0.7)$ \\
All the above mentioned reasons & $37(12.9)$ \\
\hline
\end{tabular}


knowledge. Approximately $46 \%$ of the subjects acknowledged that paracetamol overdose could damage renal failure, liver failure, gastric irritability, and immune suppression. On the time limit after which the syrup becomes invalid, $44.6 \%$ considered this limit to be the expiry date, whereas $20.6 \%$ considered this limit to be up to 6 months after opening. Regarding the participants' knowledge score, $9.8 \%$ of the subjects achieved a score of $0,32.8 \%$ achieved a score of 1 , whereas only $18.4 \%$ achieved a four or higher score (Table 5).

\section{Parents' paracetamol-related practices}

Table 6 summarizes the participating parents' answers on items that assessed paracetamol-related practices. A third (33.8\%) of the subjects preferred suppository dosage forms, a fourth $(25.4 \%)$ chose syrup as their preferred dosage form, and only $1.7 \%$ used paracetamol drops for their children. Furthermore, this study reported that some parents have difficulties in administering medications to their children. Child refusal to swallow the medication was the difficulty most encountered by parents during paracetamol administration to children. The majority of the participating parents (51.2\%) reported that health care providers (doctors and pharmacists) were their primary source of information on medication use.

\section{Discussion}

This study assessed parents' knowledge and their choice of paracetamol dosage forms for their children. The current study drove us to highlight the most commonly used OTC drug (paracetamol) and the most age categories at risk for intoxication with paracetamol unintentionally by evaluating the knowledge of parents using paracetamol for their children. In addition, the present study was designed to have an obvious image of parents' practices and attitudes toward paracetamol and to assess the basic knowledge of the parents. The availability of paracetamol and other analgesic medications such as OTC suggests that the bulk of the communities with mild to moderate pain symptoms are self-medicated. However, the general public needs to be aware of the potential risks of paracetamol misuse and overdose [43]. Observational studies are a perfect occasion for providing correct knowledge and inspire learning to parents and the community [44]. Therefore, health researchers can make a difference if taking advantage for health education.

We found that half of the participants (50.9\%) had previously used paracetamol as an antipyretic to their children. A similar percentage $(50.7 \%)$ of them reported administering paracetamol to their children without consulting a doctor. Despite these high paracetamol use
Table 5 Participating parents' responses to questions regarding knowledge of paracetamol use

\begin{tabular}{ll}
\hline Variable & Frequency (\%); $\boldsymbol{N = 2 8 7}$ \\
\hline Temperature at which paracetamol is given as antipyretic \\
$38^{\circ} \mathrm{C}$ & $111(38.7)$ \\
$38.5^{\circ} \mathrm{C}$ & $77(26.8)$ \\
$39^{\circ} \mathrm{C}$ & $69(24.0)$ \\
$39.5^{\circ} \mathrm{C}$ & $9(3.1)$ \\
$40^{\circ} \mathrm{C}$ & $1(0.3)$ \\
I don't know & $20(7.0)$
\end{tabular}

Daily maximum frequency of paracetamol use

$\begin{array}{ll}\text { One dose } & 9(3.1) \\ \text { Two doses } & 55(19.2)\end{array}$

Three doses $121(42.2)$

Four doses $78(27.2)$

Five doses $13(4.5)$

I don't know 11 (3.8)

Time allowed between doses

Less than $4 \mathrm{~h} \quad 18(6.3)$

4-6h $175(61.0)$

More than $6 \mathrm{~h} \quad 78$ (27.2)

I don't know 16 (5.6)

Time allowed for use after opening a syrup

$\begin{array}{ll}\text { Up to } 3 \text { months } & 62(21.6) \\ \text { Up to } 6 \text { months } & 59(20.6) \\ \text { Until the expiry date } & 128(44.6) \\ \text { I don't know } & 38(13.2)\end{array}$

Paracetamol overdose can cause serious adverse effects

$\begin{array}{ll}\text { Yes } & 146(50.9) \\ \text { No } & 66(23.0) \\ \text { I don't know } & 75(26.1)\end{array}$

Type of damage paracetamol overdose causes ${ }^{\mathrm{a}}$

$\begin{array}{ll}\text { Renal failure } & 46(31.5) \\ \text { Liver damage } & 42(28.8) \\ \text { Gastric irritability } & 23(15.8) \\ \text { Immune suppression } & 21(14.4) \\ \text { Other } & 14(9.5) \\ \text { Knowledge Score (out of 6) } & \\ 0 & 28(9.8) \\ 1 & 94(32.8) \\ 2 & 60(20.9) \\ 3 & 52(18.1) \\ 4 & 40(13.9) \\ 5 & 9(3.1) \\ 6 & 4(1.4)\end{array}$

${ }^{a}$ Only participants who agreed with the previous item answered this one 
Table 6 Participating parents' responses to questions on paracetamol-related practices

\begin{tabular}{ll}
\hline Variable & $\begin{array}{l}\text { Frequency (\%); } \\
N=287\end{array}$ \\
\hline
\end{tabular}

Pharmaceutical dosage form preferred

$73(25.4)$

Syrup

$97(33.8)$

Suppositories

$112(39.0)$

Syrup and suppositories

$5(1.7)$

Drops

$106(36.9)$

$125 \mathrm{mg} / 5 \mathrm{ml}$

93 (32.4)

$250 \mathrm{mg} / 5 \mathrm{ml}$

$88(30.7)$

Didn't use before

Syrup measuring tool used before

$\begin{array}{ll}\text { Teaspoon } & 10(3.5) \\ \text { Table spoon } & 14(4.9) \\ \text { Syringe } & 178(62.0) \\ \text { Measuring cup } & 2(0.7) \\ \text { Didn't use before } & 83(28.9)\end{array}$

Suppository dose used before

$\begin{array}{ll}80 \mathrm{mg} & 27(9.4) \\ 150 \mathrm{mg} & 83(28.9) \\ 250 \mathrm{mg} & 48(16.7) \\ 300 \mathrm{mg} & 64(22.3) \\ 80 \mathrm{mg} \text { and } 150 \mathrm{mg} & 6(2.1) \\ \text { Didn't use before } & 59(20.6)\end{array}$

Reasons for choosing this dosage form

$\begin{array}{ll}\text { Price } & 11(3.8) \\ \text { Efficacy } & 94(32.8) \\ \text { Doctor's recommendation } & 72(25.1) \\ \text { Pharmacist's recommendation } & 36(12.5) \\ \text { Other's recommendation } & 12(4.2) \\ \text { Easily used } & 35(12.2) \\ \text { Other } & 27(9.4)\end{array}$

Fever management if no improvement within $2 \mathrm{~h}$

$\begin{array}{ll}\text { Give another dose of paracetamol } & 61(21.3) \\ \text { Use other medications } & 37(12.9) \\ \text { Use cold sponges } & 87(30.3) \\ \text { Consult a doctor } & 90(31.4) \\ \text { Use cold sponges and consult a doctor } & 4(1.4) \\ \text { Other } & 8(2.8)\end{array}$

Reasons for using paracetamol without prescription

$\begin{array}{ll}\text { I do not trust the healthcare system } & 10(3.5) \\ \text { No need to visit the doctor } & 84(29.3) \\ \text { Doctor fee is too expensive } & 38(13.2) \\ \text { Prior experience with similar symptoms } & 104(36.2) \\ \text { Other } & 51(17.8)\end{array}$

Table 6 Participating parents' responses to questions on paracetamol-related practices (Continued)

\begin{tabular}{ll}
\hline Variable & $\begin{array}{l}\text { Frequency (\%); } \\
\mathbf{N = \mathbf { 2 8 7 }}\end{array}$ \\
\hline $\begin{array}{l}\text { Difficulty with administration } \\
\text { Children refuse to swallow the medication }\end{array}$ & $104(36.2)$ \\
Child is not cooperative due to illness & $42(14.6)$ \\
Child is sleeping at the dose time & $28(9.8)$ \\
No difficulty & $100(34.8)$ \\
Other & $13(4.5)$
\end{tabular}

Ways to ensure the child has taken the medication

$\begin{array}{ll}\text { Using force } & 54(18.8) \\ \text { Coaxing and encouraging the child } & 76(26.5) \\ \text { Mixing medicine with food or drinks } & 48(16.7) \\ \text { Seeking medical advice } & 18(6.3) \\ \text { Using non-pharmacological methods } & 10(3.5) \\ \text { Using suppositories instead of syrup } & 69(24.0) \\ \text { Other } & 9(3.1) \\ \begin{array}{l}\text { Mixing medicine with food or drinks and using } \\ \text { suppositories }\end{array} & 3(1.0)\end{array}$

\section{Reason for repeating the dose}

$\begin{array}{ll}\text { Severity of illness } & 106(36.9) \\ \text { Age } & 43(15.0) \\ \text { Weight } & 37(12.9) \\ \text { Medication leaflet } & 47(16.4) \\ \text { Doctor's consultation } & 43(15.0) \\ \text { Pharmacist's consultation } & 11(3.8)\end{array}$

Sources of information on paracetamol dose

$\begin{array}{ll}\text { Doctor's consultation } & 96(33.4) \\ \text { Pharmacist's consultation } & 51(17.8) \\ \text { Own knowledge } & 43(15.0) \\ \text { Relatives and friends } & 42(14.6) \\ \text { Experience from previous use } & 41(14.3) \\ \text { Medication leaflet } & 14(4.9)\end{array}$

Dose quantity is determined by

$\begin{array}{ll}\text { Weight } & 78(27.2) \\ \text { Age } & 73(25.4) \\ \text { Severity of illness } & 61(21.3) \\ \text { Experience from previous use } & 19(6.6) \\ \text { Medication leaflet and weight } & 52(18.1) \\ \text { Other } & 4(1.4)\end{array}$

rates, we found incorrect answers in some aspects regarding paracetamol administration, dose, and toxicity.

A third of the participants reported a preference for the suppository dosage form used. Ninety-four parents (32.8\%) justified their choices (either syrup, suppositories, or drops) as its higher efficacy compared to other 
dosage forms, and a small percentage (12.2\%) reported convenience as the reason behind their choice. However, the official recommendation states that the oral route for paracetamol administration is generally preferred in children, while the liquid form allows for more precision in estimating the right dose. In comparison, the rectal route results in slower and incomplete absorption [45]. Besides, rectal paracetamol products have many drawbacks, such as slower and more erratic absorption, varying blood concentration, insufficient therapeutic outcome, and a higher risk of toxicity [17].

According to our results, most parents (62\%) stated that they used a syringe when measuring the dose of paracetamol syrup, whereas $8.4 \%$ admitted to the use of inaccurate measuring tools, such as tablespoons and teaspoons. This matches the findings observed in earlier studies [46], which reported that regular kitchen spoons were still being used to administer medications to children at home. This, in turn, may be contributing to the high rates of inaccurate dosing of paracetamol in young children by parents. Medical personnel was the main source of medication information among parents in our sample. This result is in concordance with the results of a similar Israeli study [17] wherein $57.2 \%$ identified medical personnel as their primary source of information on paracetamol use. On the other hand, $14.6 \%$ of parents reported that they obtained information on paracetamol from relatives and friends. Therefore, enhancing access to reliable and precise information about paracetamol is mandatory to promote the safe and effective use of the most worldwide consumed analgesics and antipyretics. Physicians, community pharmacists, and information provided by medication package inserts must provide accurate information and precise instructions to parents regarding paracetamol use. Health education and promotion campaigns should also replace other unreliable sources, such as relatives and friends, with knowledge related to appropriate paracetamol use. Most patients in Palestine seek self-medication directly from community pharmacies for mild to moderate pain because they are easier to access and less costly than physicians' clinics. Paracetamol has become the medication choice for many patients, community pharmacies, and physicians in the treatment of mild to moderate pain and fever with its safe stomach profile, low cost, and OTC convenience [43]. Unfortunately, paracetamol's wide variety of brands, OTC status, lack of national paracetamol poisoning data, and lack of public health education programs to raise awareness and knowledge on paracetamol in the general population have perpetuated the illusion that paracetamol is fully benign $[35,37,43]$.

On the question of paracetamol overdose damage, only $50.9 \%$ of the parents in our sample were aware of potential harm from paracetamol overdose. On a related note,
$21.3 \%$ of parents stated that they would give another dose of paracetamol within $2 \mathrm{~h}$ after the first dose if there was no improvement. This further supports the idea that dose miscalculation and lack of knowledge of the appropriate dose timing could be behind many reported cases of severe hepatic damage or even death from paracetamol products. Knowing the maximum daily dose is of great importance since most toxicity cases occur from exceeding the recommended daily dose. In this study, the majority of the parents demonstrated inaccurate knowledge in this area. These results agreed with those observed in a survey conducted in the United States in which only a third of the subjects knew the correct maximum daily dose [45]. The American Academy of Pediatrics' recommendation states that clear written information on paracetamol should be given to caregivers during the well-child visit on multiple occasions [47].

Another interesting finding was that $36.9 \%$ of the participating parents stated that the severity of the illness was the determinant of the dose they would give. This is in collision with the recommendation regarding agebased dose scheduling, which suggests allowing for an incremental increase in the dose with growth, not with illness severity [48].

Knowledge among participants regarding paracetamol administration, dosing, and toxicity was rated by a score of $0-6$, with $81.6 \%$ of our participants achieving $\leq 3$ points. This result indicates insufficient knowledge regarding paracetamol use among caregivers. Combined with the finding that more than a third of the participants stated that they had used paracetamol without consulting a doctor because they reckoned they had had enough knowledge from experience with previous illness in children. These findings are concerning and warrant immediate interventions that aim to increase the level of awareness and provide accurate and adequate knowledge for parents and the general population regarding paracetamol use.

\section{Strengths and limitations}

This was the first study in Palestine to assess parents' knowledge regarding paracetamol. The study covered the topic of paracetamol use in children from different angles, including product identification, dose-related knowledge, dosage form, storage, administration, and toxicity. On the other hand, this study had some limitations. First, we used a convenient sampling for participants' selection. Moreover, most of the study subjects were females, which may have limited the representability of our sample and they were not reviewed after the doctor's instructions. It also limited our ability to examine any gender-related differences in parental knowledge. Because we studied only one area, our findings may not 
accurately reflect all parents' situation in Palestine. Furthermore, the cross-sectional design that was adopted in the current study did not allow for testing causality between variables. In addition, the absence of control groups (i.e., parents with children versus parents without children) limits the interpretation of paracetamol burden on parents' knowledge and awareness. Finally, the recall bias and language level of complexity could not be eliminated completely due to limitations in such studies.

\section{Conclusions}

This study showed that there were inadequate information and awareness among Palestinian parents about the use of paracetamol. This knowledge gap was evident in different areas, including paracetamol dosing, administration timing, and toxicity potential. Accordingly, we recommend raising awareness regarding this problem among parents and working on plans to provide caregivers with accurate and adequate information on dosing, formulation, side effects, and other aspects of paracetamol use. Moreover, we recommend assessing knowledge among health care professionals regarding paracetamol as doctors and pharmacists are the main sources of information for the majority of parents. Therefore, we can ensure parents are provided with accurate and adequate information regarding medication. However, the findings shed light on parents' behavior, strengthening their knowledge that can be used to raise public awareness about the risks of paracetamol. In addition, appropriate strategies are also needed to reduce parental errors in paracetamol administration for children. To bridge the gap in the rational use of paracetamol, healthcare providers and public health officials should work together.

\section{Supplementary Information}

The online version contains supplementary material available at https://doi. org/10.1186/s12889-021-10432-5

Additional file 1. Study questionnaires. This is the final English version of the questionnaire used to obtain data that helps to evaluate parents knowledge, attitudes, and practice regarding paracetamol dosing and toxicity and their awareness regarding paracetamol-containing products in Palestine.

\section{Abbreviations}

OCT: Over the counter; IRB: Institutional Review Board

\section{Acknowledgements}

The authors would like to thank the Palestinian Ministry of Health for granting permission to collect the data from primary health care centres.

\section{Authors' contributions}

$A D, R J, F A, M E$, and $Z S$, performed data collection and analysis, reviewed the literature, and contributed to drafting the manuscript. AS, AK, and SA performed data analysis, reviewed the literature, and assessed data interpretation and manuscript drafting. SZ conceptualized and designed the study, coordinated, supervised, and was responsible for the data integrity and analysis accuracy; he critically reviewed the interpretation of the results and assisted in the final write-up. All authors read the final manuscript and approved it.

\section{Funding}

None.

\section{Availability of data and materials}

The datasets used and/or analyzed during the current study are available from the corresponding author on reasonable request.

Ethics approval and consent to participate

This study had received approval from the Institutional Review Board (IRB) of An-Najah National University (Archived number 6/August/2016), as well as approval from the Palestinian ministry of health. Verbal consent for participation was obtained from all parents or guardians before they were interviewed. The IRB has accepted that verbal consent is appropriate to carry out this study due to the fact that none of the survey items related to personal ethical issues.

\section{Consent for publication}

Not applicable.

\section{Competing interests}

The authors declare that they have no competing interests.

\section{Author details}

${ }^{1}$ Department of Clinical and Community Pharmacy, Department of Pharmacy, College of Medicine and Health Sciences, An-Najah National University, Nablus 44839, Palestine. ${ }^{2}$ Department of Medicine, College of Medicine and Health Sciences, An-Najah National University, Nablus 44839, Palestine. ${ }^{3}$ Poison Control and Drug Information Center (PCDIC), College of Medicine and Health Sciences, An-Najah National University, Nablus 44839, Palestine. ${ }^{4}$ Clinical Research Center, An-Najah National University Hospital, Nablus 44839, Palestine.

Received: 2 September 2020 Accepted: 12 February 2021

Published online: 18 February 2021

\section{References}

1. Jozwiak-Bebenista M, Nowak JZ. Paracetamol: mechanism of action, applications and safety concern. Acta Pol Pharm. 2014;71(1):11-23.

2. Mullan J, Burns P, Sargeant D. Caregivers' knowledge about children's paracetamol. J Pharm Pract Res. 2018;48(5):454-8.

3. Helgadóttir HL, Wilson ME. Parents' knowledge and choice of paracetamo dosing forms in 3- to 6-year-old children. Scand J Caring Sci. 2008;22(1): 93-7.

4. Jensen JF, Tønnesen LL, Söderström M, Thorsen H, Siersma V. Paracetamol for feverish children: parental motives and experiences. Scand J Prim Health Care. 2010;28(2):115-20.

5. Lagerløv $P$, Helseth $S$, Holager T. Childhood illnesses and the use of paracetamol (acetaminophen): a qualitative study of parents' management of common childhood illnesses. Fam Pract. 2003;20(6):717-23.

6. Goldman RD, Scolnik D. Underdosing of acetaminophen by parents and emergency department utilization. Pediatr Emerg Care. 2004;20(2):89-93.

7. de Bont EG, Francis NA, Dinant GJ, Cals JW. Parents' knowledge, attitudes, and practice in childhood fever: an internet-based survey. Br J Gen Pract. 2014;64(618):e10-6.

8. Zyoud SH, Al-Jabi SW, Sweileh WM. Worldwide research productivity of paracetamol (acetaminophen) poisoning: a bibliometric analysis (20032012). Hum Exp Toxicol. 2015;34(1):12-23.

9. Zyoud SH, Awang R, Sulaiman SA. Reliability of the reported ingested dose of acetaminophen for predicting the risk of toxicity in acetaminophen overdose patients. Pharmacoepidemiol Drug Saf. 2012;21(2):207-13.

10. Court MH. Genetic biomarkers of Paracetamol (acetaminophen)-induced acute liver failure. In: Patel V, Preedy V, editors. Biomarkers in Liver Disease Biomarkers in Disease: Methods, Discoveries and Applications. Dordrecht: Springer; 2017.

11. Jalan R, Williams R, Bernuau J. Paracetamol: are therapeutic doses entirely safe? Lancet. 2006;368(9554):2195-6. 
12. Dorji T, Gyeltshen K, Pongpirul K. Rational use of paracetamol among outpatients in a Bhutanese district hospital bordering India: a cross-sectional study. BMC Res Notes. 2018;11(1):660.

13. Lee WM. Acetaminophen (APAP) hepatotoxicity-lsn't it time for APAP to go away? J Hepatol. 2017;67(6):1324-31.

14. Kominek K, Pawłowska-Kamieniak A, Mroczkowska-Juchkiewicz A, Krawiec P, Pac-Kożuchowska E. Intentional and accidental paracetamol poisoning in childhood - a retrospective analysis. Postepy Hig Med Dosw (Online). 2015; 69:452-6.

15. Mund ME, Quarcoo D, Gyo C, Bruggmann D, Groneberg DA. Paracetamol as a toxic substance for children: aspects of legislation in selected countries. J Occup Med Toxicol. 2015;10:43

16. Barrett TW, Norton VC. Parental knowledge of different acetaminophen concentrations for infants and children. Acad Emerg Med. 2000;7(6):718-21.

17. Bilenko N, Tessler H, Okbe R, Press J, Gorodischer R. Determinants of antipyretic misuse in children up to 5 years of age: a cross-sectional study. Clin Ther. 2006;28(5):783-93.

18. Chang MC, Chen YC, Chang SC, Smith GD. Knowledge of using acetaminophen syrup and comprehension of written medication instruction among caregivers with febrile children. J Clin Nurs. 2012;21(1-2):42-51.

19. Cranswick N, Coghlan D. Paracetamol efficacy and safety in children: the first 40 years. Am J Ther. 2000;7(2):135-41.

20. Kapasi AA, Lorin MI, Nirken MH, Yudovich M. Parents' knowledge and sources of knowledge about antipyretic drugs. J Pediatr. 1980;97(6):1035-7.

21. Obu HA, Chinawa JM, Ubesie AC, Eke CB, Ndu IK. Paracetamol use (and/or misuse) in children in Enugu, south-east, Nigeria. BMC Pediatr. 2012;12:103.

22. Ramanayake RP, Jayasinghe $L R$, De Silva $A H$, Wijesinghe WA, Kanaganayagam N. Knowledge and practices of paracetamol administration among caregivers of pediatric age group patients. J Fam Med Prim Care. 2012;1(1):30-3.

23. Walsh A, Edwards H, Fraser J. Influences on parents' fever management: beliefs, experiences and information sources. J Clin Nurs. 2007;16(12):2331-40.

24. Mantzke US, Brambrink AM. Paracetamol in childhood. Current state of knowledge and indications for a rational approach to postoperative analgesia. Anaesthesist. 2002;51(9):735-46.

25. Hurwitz J, Sands S, Davis E, Nielsen J, Warholak T. Patient knowledge and use of acetaminophen in over-the-counter medications. J Am Pharm Assoc (2003). 2014;54(1):19-26.

26. Sawalha AF. Poison control and the drug information center: the Palestinian experience. Isr Med Assoc J. 2008;10(11):757-60.

27. Sweileh WM. Pain medications in Palestinian households: safety and wastage analysis. Int J Risk Saf Med. 2009:21(4):193-200

28. Cairns R, Brown JA, Wylie CE, Dawson AH, Isbister GK, Buckley NA. Paracetamol poisoning-related hospital admissions and deaths in Australia, 2004-2017. Med J Aust. 2019;211(5):218-23.

29. Zyoud SH, Al-Jabi SW, Bali Yl, Al-Sayed AM, Sweileh WM, Awang R. Availability of treatment resources for the management of acute toxic exposures and poisonings in emergency departments among various types of hospitals in Palestine: a cross-sectional study. Scand J Trauma Resusc Emerg Med. 2014;22:13.

30. Fontana RJ. Acute liver failure including acetaminophen overdose. Med Clin North Am. 2008;92(4):761-94 viii.

31. Hawkins LC, Edwards JN, Dargan PI. Impact of restricting paracetamol pack sizes on paracetamol poisoning in the United Kingdom: a review of the literature. Drug Saf. 2007;30(6):465-79.

32. Manthripragada AD, Zhou EH, Budnitz DS, Lovegrove MC, Willy ME. Characterization of acetaminophen overdose-related emergency department visits and hospitalizations in the United States. Pharmacoepidemiol Drug Saf. 2011;20(8):819-26.

33. Tariq M, Din F. Poor knowledge of university students regarding paracetamol; a wakeup call for public healthcare practitioners. Cogent Medicine. 2017;4(1):1320848.

34. Lau SM, McGuire TM, van Driel ML. Consumer concerns about paracetamol: a retrospective analysis of a medicines call Centre. BMJ Open. 2016;6(6): e010860.

35. Se Z, Shtaya RM, Hamadneh DQ, Sawalmeh SN, Khadrah HA, Zedat RR, Othman A, Sweileh WM, Awang R, Al-Jabi SW. Parental knowledge, attitudes, and practices towards self-medication for their children: a crosssectional study from Palestine. Asia Pac Fam Med. 2019;18(1):61.
36. Al-Ramahi RJ, Zaid AAN, Anabousi H. Problems associated with reconstitution, administration, and storage of antibiotic suspensions for pediatrics: a cross-sectional study in Nablus city, Palestine. BMC Res Notes. 2015:8(1):760.

37. Zyoud SH, Al-Jabi SW, Sweileh WM, Nabulsi MM, Tubaila MF, Awang R, Sawalha AF. Beliefs and practices regarding childhood fever among parents: a cross-sectional study from Palestine. BMC Pediatr. 2013;13:66.

38. Zyoud SH, Abu Taha A, Araj KF, Abahri IA, Sawalha AF, Sweileh WM, Awang $\mathrm{R}, \mathrm{Al}$-Jabi SW. Parental knowledge, attitudes and practices regarding antibiotic use for acute upper respiratory tract infections in children: a crosssectional study in Palestine. BMC Pediatr. 2015;15(1):176.

39. Ali R, Shadeed A, Fitian H, Zyoud SH. The difficulties experienced during the preparation and administration of oral drugs by parents at home: a crosssectional study from Palestine. BMC Pediatr. 2020;20(1):198.

40. Zyoud SH, Al-Jabi SW, Nabulsi MM, Tubaila MF, Sweileh WM, Awang R, Walsh A. The validity and reliability of the parent fever management scale: a study from Palestine. Matern Child Health J. 2015;19(8):1890-7.

41. Daniel WW. Biostatistics: A Foundation for analysis in the health sciences. 7th ed. New York: John Wiley \& Sons; 1999.

42. Olum R, Chekwech G, Wekha G, Nassozi DR, Bongomin F. Coronavirus Disease2019: Knowledge, Attitude, and Practices of Health Care Workers at Makerere University Teaching Hospitals, Uganda. Front Public Health. 2020;8:181.

43. Sweileh WM. Utilization of acetaminophen in Palestine: toxicity and therapeutic implications. IUG J Nat Stud. 2004;12(1):25-36.

44. National Academies of Sciences; Engineering; and Medicine. Parenting Matters: Supporting Parents of Children Ages 0-8. Washington, DC: The National Academies Press; 2016.

45. Hornsby LB, Whitley HP, Hester EK, Thompson M, Donaldson A. Survey of patient knowledge related to acetaminophen recognition, dosing, and toxicity. J Am Pharm Assoc (2003). 2010;50(4):485-9.

46. You MA, Nam SM, Son YJ. Parental experiences of medication administration to children at home and understanding of adverse drug events. J Nurs Res. 2015:23(3):189-96.

47. American Academy of Pediatrics Committee on Drugs. Acetaminophen toxicity in children. Pediatrics. 2001;108(4):1020-4.

48. Temple AR. Pediatric dosing of acetaminophen. Pediatr Pharmacol (New York). 1983:3(3-4):321-7.

\section{Publisher's Note}

Springer Nature remains neutral with regard to jurisdictional claims in published maps and institutional affiliations.

Ready to submit your research? Choose BMC and benefit from:

- fast, convenient online submission

- thorough peer review by experienced researchers in your field

- rapid publication on acceptance

- support for research data, including large and complex data types

- gold Open Access which fosters wider collaboration and increased citations

- maximum visibility for your research: over $100 \mathrm{M}$ website views per year

At $\mathrm{BMC}$, research is always in progress.

Learn more biomedcentral.com/submission 